\title{
A functionalized single-walled carbon nanotube- induced autophagic cell death in human lung cells through Akt-TSC2-mTOR signaling
}

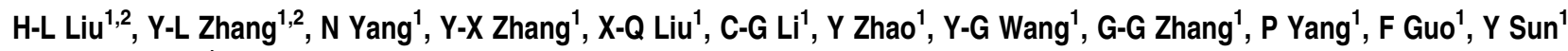 \\ and C-Y Jiang ${ }^{*, 1}$
}

Nanoparticles are now emerging as a novel class of autophagy activators. Functionalized single-walled carbon nanotubes (f-SWCNTs) are valuable nanomaterials in many industries. This article is designed to assess the autophagic response for $\mathrm{f}$-SWCNTs exposure in vitro and in vivo. A few types of f-SWCNTs were screened in human lung adenocarcinoma A549 cells for the autophagic response and related pathways in vitro. Formation of autophagosomes and LC3-II upregulation were confirmed on the basis of electron microscopy and LC3 western blotting for COOH-CNT, but not for PABS-CNT and PEG-CNT. MTT assay showed marked increase in cell viability, when $\mathrm{COOH}-\mathrm{CNT}$ was added to cells in the presence of autophagy inhibitor 3MA, ATG6 or TSC2 siRNA. Consistent with the involvement of the Akt-TSC1/2-mTOR pathway, the phosphorylation levels of mTOR, mTOR's substrate S6 and Akt were shown significantly decreased in A549 cells on treatment with COOH-CNT using western blotting. What's more, autophagy inhibitor 3MA significantly reduced the lung edema in vivo. In a word, COOH-CNT induced autophagic cell death in A549 cells through the AKT-TSC2-mTOR pathway and caused acute lung injury in vivo. Inhibition of autophagy significantly reduced $\mathrm{COOH}-\mathrm{CNT}$-induced autophagic cell death and ameliorated acute lung injury in mice, suggesting a potential remedy to address the growing concerns on the safety of nanomaterials.

Cell Death and Disease (2011) 2, e159; doi:10.1038/cddis.2011.27; published online 19 May 2011

Subject Category: Cancer

The human acute and chronic lung injury have been reported by exposure to nanoparticles or ultrafine particles as poorly defined decades ago in occupational or environmental settings; however, the underlying molecular mechanisms are unclear. $^{1-5}$ Carbon nanotubes are one of the most prominent nanomaterials, ${ }^{6-8}$ mainly consisting of multi-walled carbon nanotubes (MWCNTs) and single-walled carbon nanotubes (SWCNTS). Functionalized single-walled carbon nanotubes ( $f-S W C N T s$ ) are valuable nanomaerials in many industries, especially in biomedical applications. ${ }^{9,10}$ It is urgent to study the potential lung toxicity that f-SWCNTs could probably arouse, as well as the underlying mechanisms. Previous studies and our unpublished data have found that pulmonary inflammation had a part and parcel of role in SWCNTs-induced lung toxicity. ${ }^{11-14}$ But, does this constitute the whole truth? What will add in, especially for f-SWCNTs?

Autophagy is a degradation process in eukaryotic cells by which damaged organelles or long-lived proteins are engulfed in double-membrane vesicles for degradation and recycling. ${ }^{15}$ It has an important role in some human diseases, including cancer, neurodegenerative disorders and viral infections. ${ }^{16}$ Autophagy, acting as a balance between cell survival and death, can provide energy as a result of bulk degradation in case of energy shortage, but also can cause injury to the cells, inducing autophagic cell death as excessive autophagy leads to self-destruction of mammalian cells. ${ }^{17,18}$ Nanoparticles are now emerging as a novel class of autophagy activators, with some types of nanoparticles been found to induce autophagy in vitro. ${ }^{19-22}$ We have recently shown that a type of nanoparticle, named PAMAM G3, could induce A549 autophagic cell death and cause acute lung injury in mice. ${ }^{20}$

In this study, we want to further elucidate whether autophagic cell death, adding to the previous inflammation theory, could also have a role in f-SWCNTs-induced acute lung injury. To answer this question, we screened three f-SWCNTs obtained commercially: carboxylic acid (COOH-CNT), polyaminobenzene sulfonic acid (PABS-CNT) and polyethylene glycol (PEG-CNT) in human lung adenocarcinoma A549 cell line for the autophagic response and related pathways in vitro. Furthermore, mouse models using intratracheal instillation ${ }^{23}$ of f-SWCNTs were used to assess the weightiness of autophagy

\footnotetext{
${ }^{1}$ State Key Laboratory of Medical Molecular Biology, Institute of Basic Medical Sciences, Chinese Academy of Medical Sciences, Peking Union Medical College, Tsinghua University, Beijing 100005, China

${ }^{*}$ Corresponding author: C-Y Jiang, State Key Laboratory of Medical Molecular Biology, Institute of Basic Medical Sciences, Chinese Academy of Medical Sciences, Peking Union Medical College, Tsinghua University, Room 460, NO.5 Dongdansantiao, Beijing 100005, PR China. Tel: + 861065296908 ; Fax: + 86 10 6527 6551; Email: jiang@ @umc.edu.cn

${ }^{2}$ These authors contributed equally to this work.

Keywords: SWCNT; autophagy; mTOR; acute lung injury

Abbreviations: 3-MA, 3-methyladenine; $\mathrm{COOH}-\mathrm{CNT}$, carboxylic acid functionalized carbon nanotubes; f-SWCNTs, functionalized single-walled carbon nanotubes; HRP, horseradish peroxidase; MAP LC3, microtubule-associated protein light chain 3; MWCNTs, multi-walled carbon nanotubes; MTT assay, methylthiazol tetrazolium assay; mTOR, mammalian target of rapamycin; PCD, programmed cell death; PABS-CNT, polyaminobenzene sulfonic acid functionalized carbon nanotubes; PEG-CNT, polyethylene glycol functionalized carbon nanotubes; SWCNTs, single-walled carbon nanotubes

Received 24.11.10; revised 01.2.11; accepted 14.3.11; Edited by V De Laurenzi
} 
factor in the f-SWCNTs-induced pulmonary toxicity in vivo, hoping to reveal the underlying mechanism of ALI induced by f-SWCNTs, with the goal of providing a potential clinical available remedy for nanoparticles-induced lung injury.

\section{Results}

COOH-CNT induces A549 cell death through a nonapoptotic pathway. We first analyzed the effects of f-SWCNTs by incubating A549 cells with the three different f-SWCNTs: COOH-CNT, PABS-CNT and PEG-CNT, and monitoring cell viability. Interestingly, only $\mathrm{COOH}-\mathrm{CNT}$ significantly reduced A549 cell viability, whereas PABSCNT and PEG-CNT had no obvious effect on these cells (Figure 1a). We then tested whether $\mathrm{COOH}-\mathrm{CNT}$ induced A549 cell death through apoptosis using the TUNEL (Figures $1 \mathrm{~b}$ and $\mathrm{c}$ ) and caspase-3 assay (Figure 1d). However, we could not detect any evidence for apoptosis, indicating that $\mathrm{COOH}-\mathrm{CNT}$ induces A549 cell death through other pathways. We have also repeated the experiments in another lung cell line $\mathrm{NCl}-\mathrm{H} 1975 . \mathrm{COOH}-$ CNT could induce cell death (Supplementary Figure S1A), but not through apoptosis (Supplementary Figures S1B,
S1C), suggesting other mechanism is involved in the $\mathrm{COOH}-$ CNT-induced cell death.

COOH-CNT induces autophagic cell death. To examine whether these functionalized nanotubes could induce autophagy in vitro, we incubated them with the A549 cells and analyzed the samples by transmission electron microscopy to detect autophagosome accumulation, a hallmark of autophagy. ${ }^{24}$ Only $\mathrm{COOH}-\mathrm{CNT}$ induced autophagosome accumulation in these cells, whereas PABSCNT and PEG-CNT did not (Figures $2 a$ and $b$ ).

The microtubule-associated protein light chain 3 (MAP LC3)-II, a lipidated form of the cytosolic MAP LC3-I, is a determinate marker of autophagy activation. ${ }^{25}$ Cellular lysate from cells treated with f-SWCNTs were analyzed by LC3 western blotting, showing that LC3-II migrated faster than LC3-I. An increase in LC3 II protein levels in the lysates of A549 cells treated with $\mathrm{COOH}-\mathrm{CNT}$ was confirmed by the western and the densitometry values for the LC3-II (Figures $2 \mathrm{c}$ and d), whereas PABS-CNT and PEG-CNT did not induce LC3-II upregulation (Figures $2 \mathrm{c}$ and $\mathrm{d}$ ). Taken together, these results showed $\mathrm{COOH}-\mathrm{CNT}$, in contrast to PABS-CNT and PEG-CNT, induced autophagy in A549 cells.

a

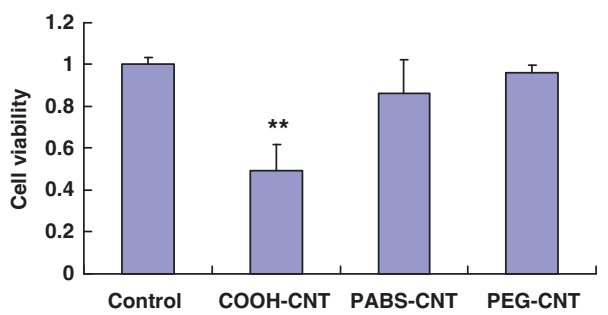

b
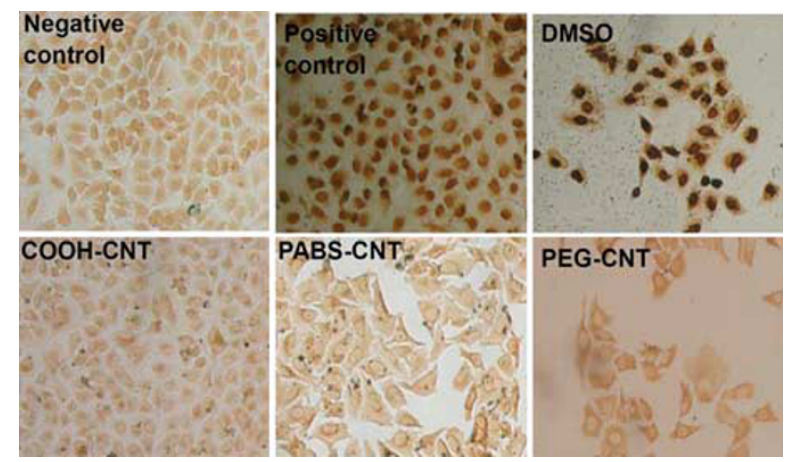

c

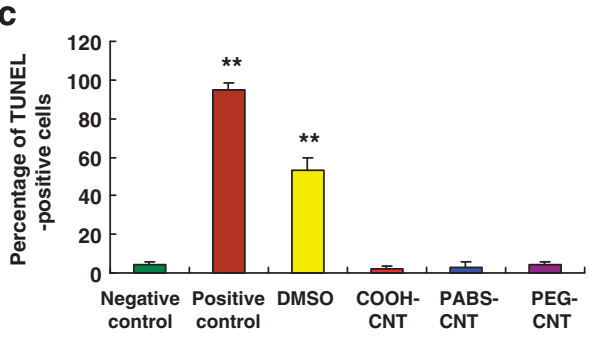

d

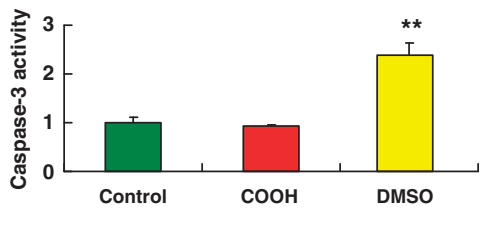

Figure $1 \mathrm{COOH}-\mathrm{CNT}$ induces A549 cell death, but not via apoptosis. (a) Cell viability of A549 cells after control, COOH-CNT, PABS-CNT and PEG-CNT treatment. ${ }^{* *} P<0.01$. (b) Representative TUNEL images of A549 cells after negative control, positive control, DMSO, COOH-CNT, PABS-CNT and PEG-CNT treatment. (c) Percentage of TUNEL-positive cells after negative control, positive control, DMSO, COOH-CNT, PABS-CNT and PEG-CNT treatment. (d) Caspase-3 activity in A549 cells after control, $\mathrm{COOH}-\mathrm{CNT}$ and DMSO treatment 
Autophagy is likened to the opposite faces of Janus, as it protects eukaryotic cells to survive certain severe conditions, as well as inducing cell death when too much autophagy occurs. ${ }^{17,18,26}$ To determine whether autophagy directly contribute to the cell death induced by $\mathrm{COOH}-\mathrm{CNT}$, we measured the cell viability of A549 cells, with treatment of the

a

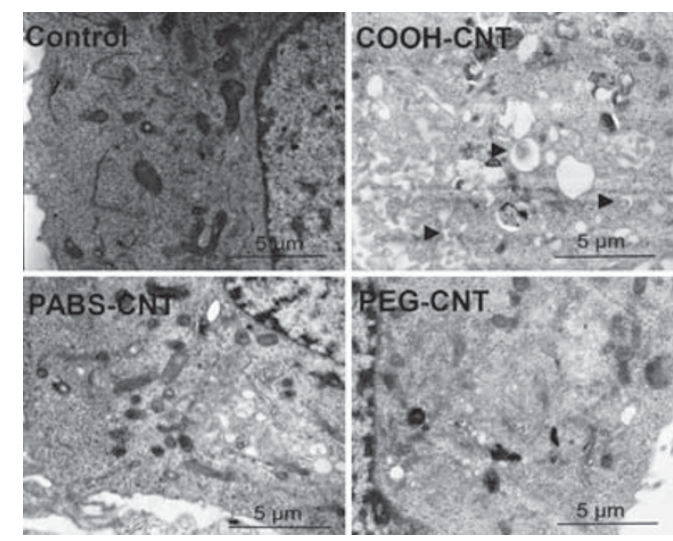

b

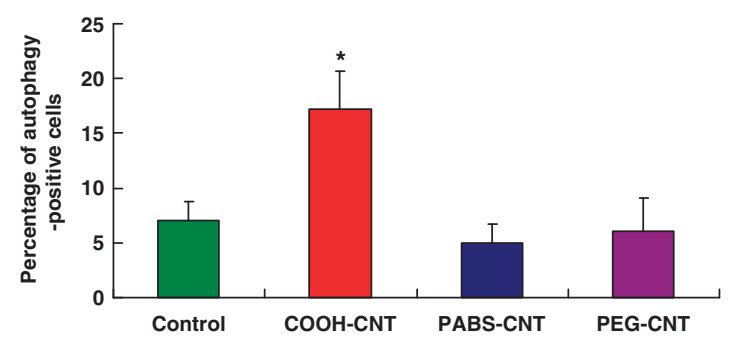

c

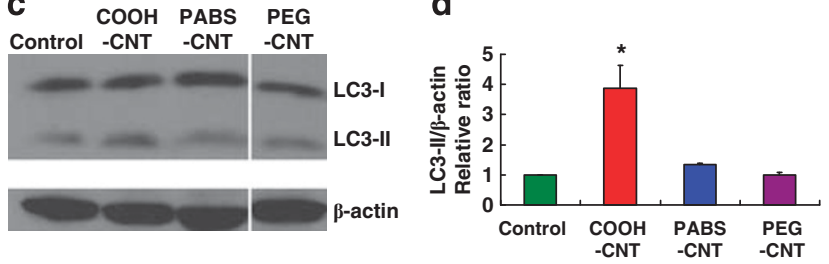

e
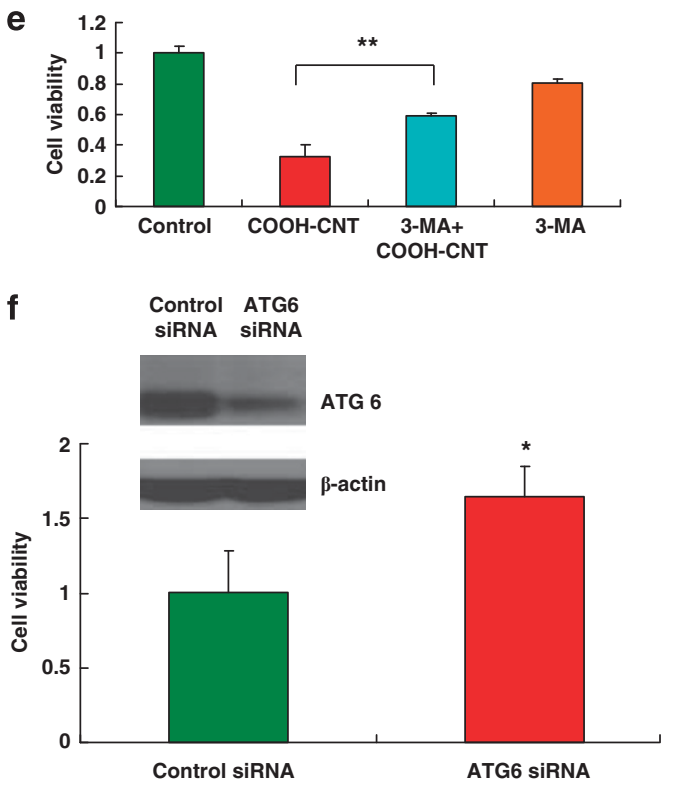

autophagy inhibitor, 3-methyladenine (3-MA), ${ }^{27}$ or siRNA knockdown of the autophagy-related gene, ATG6, using the methylthiazol tetrazolium (MTT) assay. Our results showed that cell viability in the $\mathrm{COOH}-\mathrm{CNT}$ treatment group was significantly improved when autophagy was inhibited by 3-MA or ATG6 siRNA (Figures $2 e$ and $f$ ), as compared with cells treated with vehicle or control SiRNA, suggesting that autophagy has a pro-death role in $\mathrm{COOH}-\mathrm{CNT}$-induced A549 cell death. We have repeated these experiments with human lung cell line $\mathrm{NCl}-\mathrm{H} 1975$, the results suggested that $\mathrm{COOH}-\mathrm{CNT}$ could induce autophagic cell death in $\mathrm{NCl}-\mathrm{H} 1975$ as well (Supplementary Figures S2A-E).

AKT-TSC2-mTOR signaling pathway is involved in COOH-CNT-induced autophagy. Several pathways seem to regulate autophagy in mammalian cells. Similar to yeast, the classical pathway regulating autophagy involves the serine/threonine kinase, mammalian target of rapamycin (mTOR). ${ }^{28,29}$ Under normal conditions, mTOR exists in a phosphorylated form and suppresses autophagy. When its phosphorylation level is downregulated, for example, by rapamycin or nutrient starvation, autophagy is induced. ${ }^{30}$ To test the role of mTOR in $\mathrm{COOH}-\mathrm{CNT}$-induced autophagy, we analyzed the phosphorylation levels of mTOR by western blotting and found that $\mathrm{COOH}-\mathrm{CNT}$ reduced the ratio of phosphorylated mTOR versus total mTOR compared with the control (Figures $3 a$ and $b$ ). We also discovered that the phosphorylation level of the ribosomal protein S6, a known substrate of mTOR, was downregulated by $\mathrm{COOH}-\mathrm{CNT}$ (Figures $3 \mathrm{c}$ and $\mathrm{d}$ ), again illustrating that mTOR is inhibited. It has been reported that suppression of autophagy by mTOR is regulated by the $\mathrm{PI} 3 \mathrm{~K}-\mathrm{AKT}-\mathrm{TSC} 1 / 2$ pathway. ${ }^{17,29,31}$ To further investigate the signaling events during $\mathrm{COOH}-\mathrm{CNT}$ induced-autophagy, we used a TSC2 siRNA assay to knockdown the levels of TSC2. The results showed that TSC2 siRNAs significantly improved cell viability on treatment with $\mathrm{COOH}-\mathrm{CNT}$ (Figure 3e), suggesting that TSC2 is required for $\mathrm{COOH}-\mathrm{CNT}$-induced autophagic cell death. To confirm this, we analyzed levels of phosphorylated Akt, which is upstream of TSC2. As expected, on treatment with $\mathrm{COOH}-\mathrm{CNT}$, levels of phosphorylated AKT were significantly decreased (Figures $3 f$ and $g$ ). Taken together, these results indicated that $\mathrm{COOH}-\mathrm{CNT}$ induced autophagy through the AKT-TSC2-mTOR pathway (Figure 3h).

Autophagy inhibitor ameliorates acute lung injury induced by $\mathrm{COOH}-\mathrm{CNT}$ in vivo. Nanoparticles could easily be inhaled during production or usage. As A549 cells

Figure $2 \mathrm{COOH}-\mathrm{CNT}$ induces autophagic cell death in A549 cells. (a) Electron micrographs of A549 cells after control, COOH-CNT, PABS-CNT and PEG-CNT treatment for $24 \mathrm{~h}$. (b) Percentage of autophagy-positive cells after control, $\mathrm{COOH}$ CNT, PABS-CNT and PEG-CNT treatment. ${ }^{*} P<0.05$. (c) LC3 western blotting of A549 cells after control, COOH-CNT, PABS-CNT and PEG-CNT treatment. (d) Relative ratio of LC3-II/ $\beta$-actin in control, COOH-CNT-, PABS-CNT- and PEGCNT-treated A549 cells. ${ }^{*} P<0.05$. (e) Cell viability of A549 cells after control, $\mathrm{COOH}-\mathrm{CNT}$, 3-MA plus $\mathrm{COOH}-\mathrm{CNT}$ and 3-MA treatment. ${ }^{*} P<0.01$. (f) Cell viability of A549 cells transfected with control siRNA or ATG6 siRNA after $\mathrm{COOH}$ CNT treatment. The expression of ATG6 in control siRNA and ATG6 siRNA-treated cells was detected by western blotting. ${ }^{*} P<0.05$ 


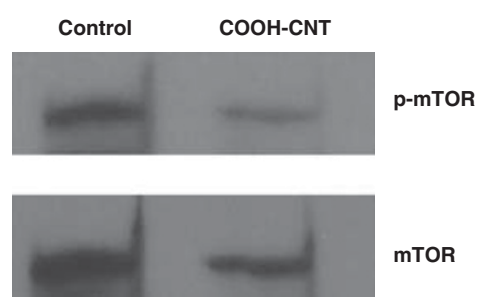

C
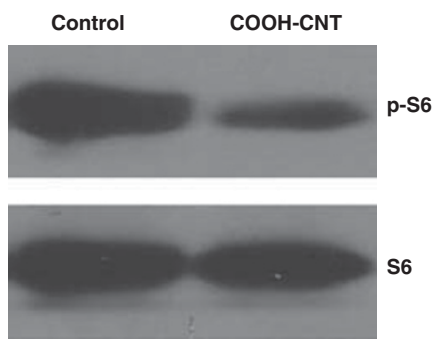

e

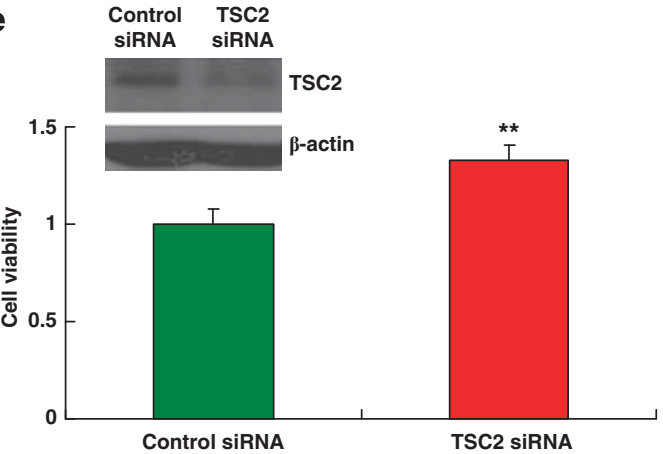

g

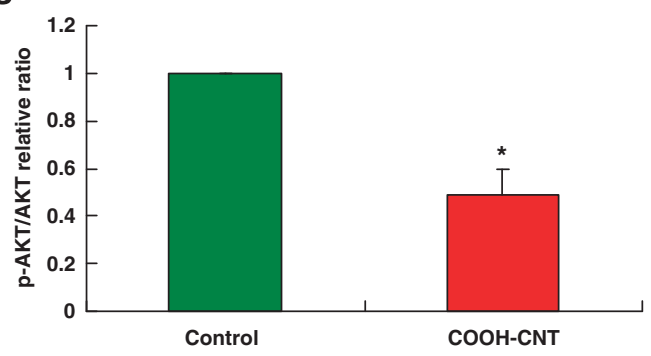

b

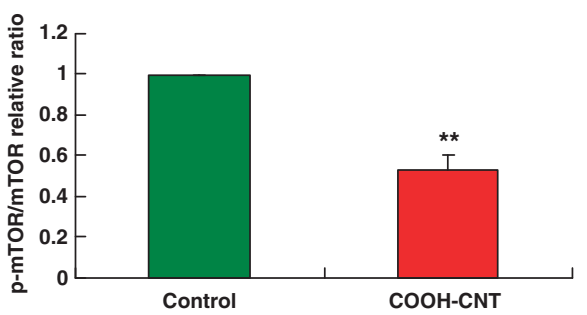

d

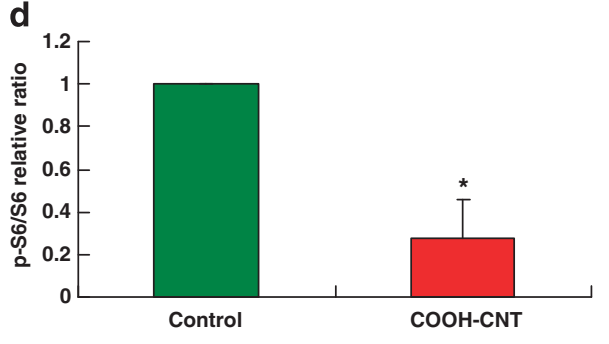

f
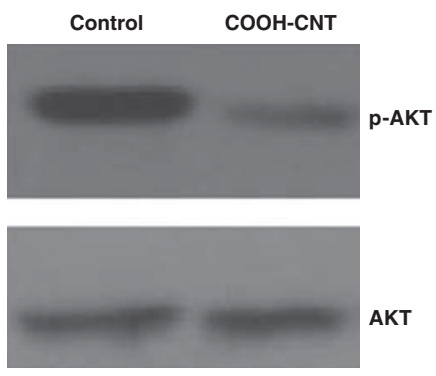

h

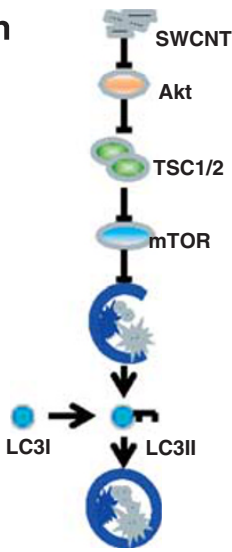

Figure $3 \mathrm{COOH}-\mathrm{CNT}$ induces autophagy in A549 cells through the AKT-TSC2-mTOR signaling pathway. (a) Western blotting to detect levels of phospho-mTOR and mTOR in control and COOH-CNT-treated A549 cells. (b) Relative ratio of the band density of phospho-mTOR to that of mTOR. The experiment was repeated at least three times. ${ }^{\star \star} P<0.01$. (c) Western blotting to detect phospho-S6 and S6 levels in control and COOH-CNT-treated A549 cells. (d) Relative ratio of the band density of phospho-S6 to that of S6. The experiment was repeated at least three times. ${ }^{*} P<0.05$. (e) Cell viability of A549 cells transfected with control siRNA or TSC2 siRNA after COOH-CNT treatment. The expression of TSC2 in control siRNA and ATG6 siRNA group was detected by western blotting ${ }^{\star \star} P<0.01$. (f) Western blotting to detect phospho-AKT and AKT levels in control and COOH-CNT-treated A549 cells. (g) Relative ratio of the band density of phospho-AKT to that of AKT. The experiment was repeated at least three times. ${ }^{\star} P<0.05$. (h) Schematic representation of the signaling pathways in $\mathrm{COOH}-\mathrm{CNT}$-induced autophagy

are derived from human lung epithelium, we therefore speculated that autophagic cell death might be induced by $\mathrm{COOH}-\mathrm{CNT}$ in the epithelial cells of the lung in vivo. We administered carbon nanotubes intratracheally into mice, and the electron microscope images of mice lung tissue showed that $\mathrm{COOH}-\mathrm{CNT}$ induced significantly more autophagosome accumulation than vehicle control lung tissue (Figures $4 a$ and b). We analyzed the histopathology of the lung. More severe lung inflammations, as shown by histopathology and leukocyte infiltration, were observed in the f-SWCNT-treated groups compared with the control group, especially in the $\mathrm{COOH}-\mathrm{CNT}$-treated group (Figures $4 \mathrm{c}$ and $\mathrm{d}$ ). When the 
a
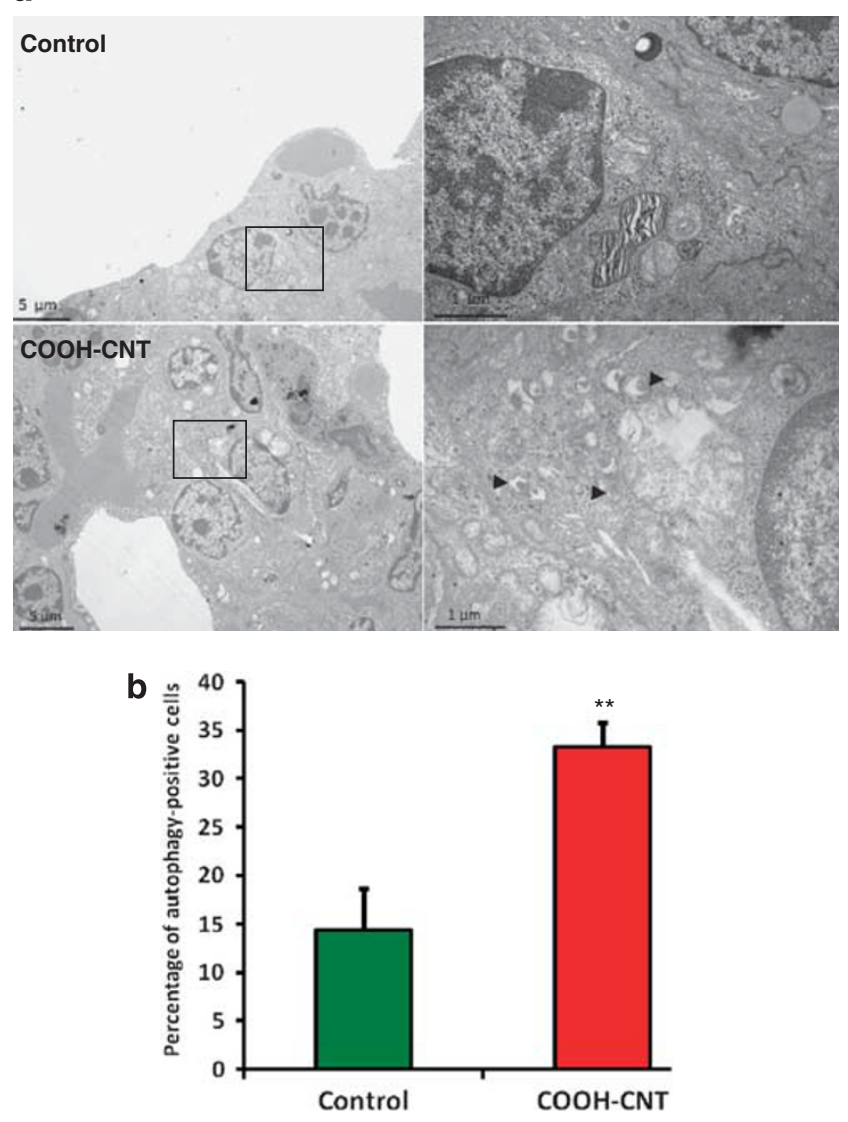

C
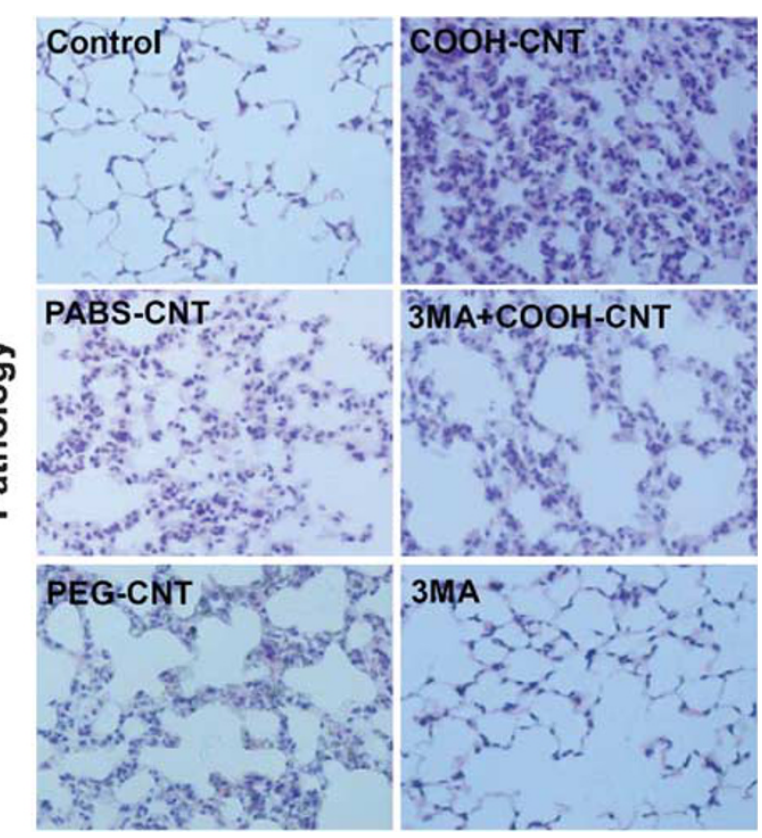

d

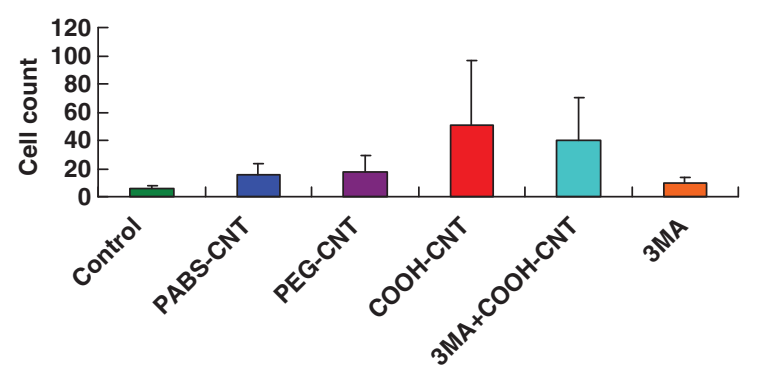

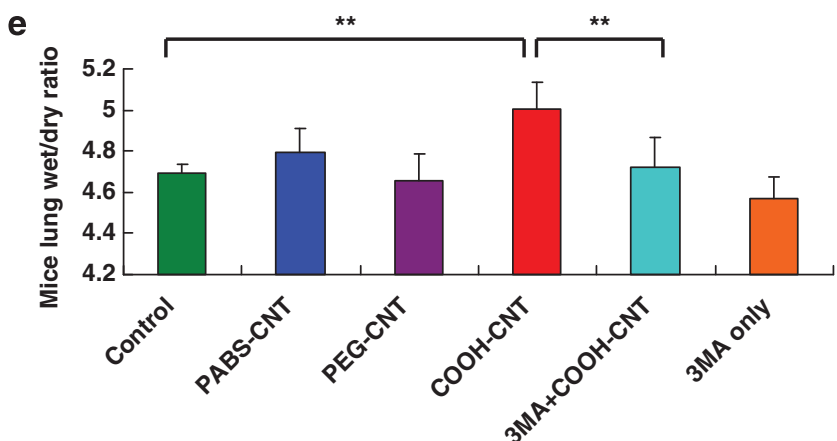

Figure 4 Autophagy has an important role in $\mathrm{COOH}-\mathrm{CNT}$-induced acute lung injury in mice. (a) Electronic microscopy images of mice lung cells after control, $\mathrm{COOH}-\mathrm{CNT}$ treatment for $9 \mathrm{~h}$. (b) Percentage of autophagy-positive cells after control, COOH-CNT treatment. (c) HE staining of the mice lung tissue after intratracheal administration of control, PABS-CNT, PEG-CNT, COOH-CNT, 3-MA plus COOH-CNT and 3-MA. (d) The number of infiltrated leukocytes in the lung tissue of control, PABS-CNT-, PEG-CNT-, COOH-CNT-, 3-MA plus COOH-CNT- and 3-MA-treated mice. (e) The lung wet/dry ratios of the mice after intratracheal administration of control, PABS-CNT, PEG-CNT, $\mathrm{COOH}-\mathrm{CNT}$, 3-MA plus $\mathrm{COOH}-\mathrm{CNT}$ and 3-MA, for $24 \mathrm{~h} .{ }^{* \star} \mathrm{P}<0.01$

autophagy inhibitor 3MA was injected intraperitoneally before administration of $\mathrm{COOH}-\mathrm{CNT}$, the level of inflammation was reduced (Figures $4 \mathrm{c}$ and $\mathrm{d}$ ). Furthermore, the mice lung wet/dry weight ratio assay after different nanotube exposure revealed that $\mathrm{COOH}-\mathrm{CNT}$ could induce more severe lung edema, which could be partially rescued by $3 \mathrm{MA}$ (Figure $4 \mathrm{e}$ ) or the PI3K inhibitor wortmannin (data not shown), than PABS-CNT and PEG-CNT (Figure 4e). In summary, these results illustrate that autophagy has an important role specifically in $\mathrm{COOH}-\mathrm{CNT}$-induced acute lung injury in mice.

\section{Discussion}

SWCNTs are now widely used in the electronic, optics and biomedical fields. Indeed, the annual market is estimated to exceed 5 billion US dollars by the year 2012. ${ }^{32}$ However, concerns about their safety have led to the need for 
comprehensive analyses to elucidate if and how SWCNTs can induce toxicity. ${ }^{1,33,34}$

As shown in previous studies, pulmonary inflammation was involved in the SWCNTs induced lung toxicity. ${ }^{11-14}$ Our results now suggested that autophagic cell death also contributed to $\mathrm{COOH}-\mathrm{CNTs}$-induced acute lung injury. Although autophagy is deemed to be predominantly a cell survival mechanism, a number of studies also implicate a role for autophagy in cell death. ${ }^{17,18}$ Among the three types of programmed cell death (PCD) considered to exist in present day mammals is type II autophagy. ${ }^{35}$ So far, autophagy has been reported to be induced by a few types of nanoparticles. $^{19-22}$ An interesting question is what the role of nanoparticle-induced autophagy is: Does autophagy help cells to survive or kill them? In our recent study, we found a type of nanoparticle, PAMAM G3, could induce autophagic cell death in A549 cells and cause acute lung injury in mice. ${ }^{20}$ Here, we found a similar result specifically with $\mathrm{COOH}-\mathrm{CNT}$. There was marked increase in cell viability when $\mathrm{COOH}-\mathrm{CNT}$ was added to cells in the presence of autophagy inhibitor 3MA or ATG6 siRNA. The above results suggested that $\mathrm{COOH}$ CNT-induced autophagy was pro-death. What's more, inhibition of the autophagy also ameliorated acute lung injury induced by $\mathrm{COOH}-\mathrm{CNT}$ in vivo. Our study suggested autophagy, with another ancient process inflammation, shared in the mechanisms of SWCNTs-induced lung toxicity. The weightiness of each process, however, should still be further weighed in future study.

Another interesting question arises too: How do nanoparticles trigger autophagy? Autophagy is clearly not a common response to all nanoparticles, because some types fail to induce autophagy. Size may be one important factor, as larger quantum dot could not induce autophagy in human mesenchymal stem cells. ${ }^{21}$ Surface group is another important factor, as cationic PAMAMs were more prone to inducing autophagy in A549 cells than anionic PAMAMs. ${ }^{20}$ Here, we show that carbon nanotubes with carboxylic acid group could also induce autophagy in A549 cells. On the contrary, the SWCNTs functionalized with PABS and PEG groups were not able to induce autophagy. We speculate that the structure, shape, charge and other characteristics of the functionalization groups, the size and core material of nanoparticles might, in different cases and to different extents, participate in the determination of cell fate when confronting autophagy.

Viewed from another point, our results also offered a clue for lung cancer therapy. It has been reported that many cancer chemotherapies are potent inducers of autophagy. ${ }^{36}$ In consideration that $\mathrm{COOH}-\mathrm{CNT}$ could induce autophagic cell death in human lung adenocarcinoma cells, we might exploit it as a potential therapeutic drug in lung cancer.

In conclusion, we showed that $\mathrm{COOH}-\mathrm{CNT}$ induced autophagic cell death through the AKT-TSC2-mTOR pathway in vitro and caused acute lung injury in mice, shedding light on the mechanisms of $\mathrm{f}$-SWCNTs-induced lung toxicity. We also found that use of autophagy inhibitor could reduce $\mathrm{COOH}-\mathrm{CNT}$-induced cell death and ameliorated acute lung injury, which suggested for clinicians to use autophagy-blocking reagents as potential agents to remedy the $A L I$ induced by unintentional exposure to f-SWCNTs.

\section{Materials and Methods}

Cells, carbon nanotubes, reagents and antibodies. The human lung adenocarcinoma A549 cell line was purchased from ATCC (Manassas, VA, USA), and cultured in F-12/ HAM'S (Hyclone, Logan, UT, USA) medium supplemented with 10\% FBS, $100 \mathrm{U} / \mathrm{ml}$ penicillin/streptomycin at $37^{\circ} \mathrm{C}, 5 \%$ carbon dioxide incubator.

PABS (polyaminobenzene sulfonic acid), PEG (polyethylene glycol) or $\mathrm{COOH}$ (carboxylic acid) functionalized SWCNTs were purchased from Sigma-Aldrich (St. Louis, MO, USA).

Phospho-mTOR (Ser2481), mTOR, phospho-S6, S6, phospho-AKT (Ser473), AKT and LC3B antibodies were purchased from Cell Signaling Technology (Boston, MA, USA). TSC2 and ATG6 antibodies were purchased from Santa Cruz Biotechnology (Santa Cruz, CA, USA). $\beta$-actin antibody was purchased from Sigma-Aldrich. Horseradish Peroxidase (HRP) conjugated secondary antibodies and western blotting luminal reagents were all from Santa Cruz Biotechnology.

CellTiter 96 AQueous One Solution Cell Proliferation Assay was purchased from Promega Corporation (Madison, WI, USA). Caspase-3 fluorescence determination kit was purchased from Baosai Biotech Limited Company, Beijing, China.

Dispersion of the carbon nanotubes. SWCNTs were weighted and dissolved in F-12/ HAM'S (Hyclone) medium supplemented with 10\% FBS, $100 \mathrm{U} / \mathrm{ml}$ penicillin/streptomycin. The solution was then sonicated for $1 \mathrm{~h}$ in a water bath. The final concentration of the carbon nanotubes was $5 \mathrm{mg} / \mathrm{ml}$.

MTT assay. A549 cells or $\mathrm{NCl}-\mathrm{H} 1975$ cells were seeded in 96-well plates at $1 \times 10^{5} / \mathrm{ml}$. PABS-CNT, PEG-CNT and $\mathrm{COOH}-\mathrm{CNT}$ at a final concentration of $1 \mathrm{mg} / \mathrm{ml}$ or an equal volume of vehicle (culture medium) was added to the wells on the following day. In the $\mathrm{COOH}-\mathrm{CNT}$ plus 3-MA group, 3-MA was added $1 \mathrm{~h}$ before $\mathrm{COOH}-\mathrm{CNT}$. Each condition was carried out in triplicate.

After $24 \mathrm{~h}, 20 \mu \mathrm{l}$ CellTiter 96 AQueous One Solution Cell Proliferation Assay solution was added to each well, and incubated for another $2 \mathrm{~h}$. Finally, the solution in the wells was collected in the tube and spun at 13200 r.p.m./min for $5 \mathrm{~min}$. The supernatant was collected and absorbance was then recorded with dual waves at 490 and $630 \mathrm{~nm}$.

Caspase-3 activity determination. A549 cells or NCl-H1975 cells were seeded in $6-\mathrm{cm}$ plates at $1 \times 10^{6} / \mathrm{ml}$. Five percent DMSO, COOH-CNT or an equal volume of vehicle was added to the plate the next day. After $24 \mathrm{~h}$, cells were lysed and caspase- 3 activity was determined using a caspase- 3 fluorescence kit following the manufacturer's protocol.

TUNEL assay. A549 cells or NCl-H1975 cells were seeded on coverslips in 24-well plates. PABS-CNT, PEG-CNT and COOH-CNT at a final concentration of $1 \mathrm{mg} / \mathrm{ml}$ or an equal volume of vehicle was added to the wells the next day. After $24 \mathrm{~h}$, the coverslips were washed in PBS and fixed in $4 \%$ paraformaldehyde for $1 \mathrm{~h}$ at room temperature. After blocking and permeabilization procedures, the slides were processed following the manufacturer's protocol. The slides were analyzed under a light microscope.

Western blotting. A549 cells or NCl-H1975 cells were seeded at $1 \times 10^{5} / \mathrm{ml}$ in 12-well plates. PABS-CNT, PEG-CNT and $\mathrm{COOH}-\mathrm{CNT}$ at a final concentration of $1 \mathrm{mg} / \mathrm{ml}$, or an equal volume of vehicle was added to the wells in next day. After $24 \mathrm{~h}$, cells were lysed, denatured at $97^{\circ} \mathrm{C}$ for $10 \mathrm{~min}$ and subjected to western blotting analysis. Band density was calculated using AlphaEaseFC software (Alpha Innotech, San Leandro, CA, USA).

Transmission electron microscopy. A549 cells or NCl-H1975 cells were seeded in 6-well plates at $2 \times 10^{5} / \mathrm{ml}$. PABS-CNT, PEG-CNT and COOH-CNT at a final concentration of $1 \mathrm{mg} / \mathrm{ml}$ or an equal volume of vehicle was added to the wells the next day. After $24 \mathrm{~h}$, cells were harvested by trypsin digestion and centrifuged at $800 \mathrm{~g}$ for $5 \mathrm{~min}$. After being washed twice in cold PBS, the supernatant was discarded and the cells were fixed with $2.5 \%$ glutaraldehyde in $0.1 \mathrm{M}$ sodium dihydrogen phosphate, $\mathrm{pH} 7.4$. The samples were then fixed in $1 \% \mathrm{OsO}_{4}$ for $1 \mathrm{~h}$ and dehydrated by increasing concentrations of acetone, and gradually infiltrated with epoxy resin. Ultrathin sections were obtained and stained with uranyl acetate and lead citrate. A cell containing two or more autophagosomes was defined as an autophagy positive cell.

TSC2 siRNA MTT assay. A549 cells were seeded in 24-well plates the day before being transfected with siRNA against TSC2 $(50 \mathrm{nM}$, Santa Cruz Biotechnology) or control siRNA using lipofectamine 2000 (Invitrogen, Carlsbad, $\mathrm{CA}$, USA). Another $48 \mathrm{~h}$ later, the effect of the siRNA was determined by western blot with anti-TSC2 antibody. In parallel, $24 \mathrm{~h}$ after transfection, cells were trypsin 
digested and seeded on 96-well plates. COOH-CNT $(1 \mathrm{mg} / \mathrm{ml})$ was added to the TSC2 siRNA and control siRNA group the next day, and the MTT assay was conducted on the following day.

ATG6 siRNA MTT assay. A549 cells were seeded in 24-well plates. After $24 \mathrm{~h}$, cells were transfected with siRNA against ATG6 $(100 \mu \mathrm{M}$, Santa Cruz Biotechnology) or control siRNA. Another $48 \mathrm{~h}$ later, the effect of the siRNA was determined by western blot with anti-ATG6 antibody. In parallel, $24 \mathrm{~h}$ after transfection, cells were trypsin digested and seeded on 96-well plates. $\mathrm{COOH}-\mathrm{CNT}$ $(1 \mathrm{mg} / \mathrm{ml})$ was added to the ATG6 siRNA and control siRNA group the next day, and the MTT assay was conducted on the following day.

Mouse handling. Mice were housed under specific-pathogen-free conditions Mouse experiments were conducted in the animal facility at the Institute of Basic Medical Sciences of the Peking Union Medical College in accordance with the government and institutional animal care and use committee guidelines. 6- to 10-week-old male BALB/c mice were used (Vital River, Beijing). They were caged in a specific-pathogen-free facility as groups of five or less and fed ad libitum with laboratory autoclavable rodent diet. Euthanasia was performed with pentobarbital sodium.

Mouse lung tissue histopathological examination. $24 \mathrm{~h}$ afte intratracheal administration of control, $\mathrm{COOH}-\mathrm{CNT}$, PABS-CNT, PEG-CNT, 3-MA plus $\mathrm{COOH}-\mathrm{CNT}$ and 3-MA, the Balb/c mice were killed. In the 3-MA plus $\mathrm{COOH}$ CNT group, 3-MA (15 mg/kg) was injected $1 \mathrm{~h}$ before $\mathrm{COOH}-\mathrm{CNT}$. Lungs were fixed in formalin for $48 \mathrm{~h}$ and then embedded in paraffin. $4 \mu \mathrm{m}$ sections were obtained and stained with hematoxylin-eosin. Each slide was independently examined by three different pathologists.

Mouse lung wet/dry ratio assay. The Balb/c mice were randomly grouped. After anesthesia by intraperitoneal injection with $1 \%$ pentobarbital sodium solution, they were intratracheally administrated with control, $\mathrm{COOH}-\mathrm{CNT}, \mathrm{PABS}-\mathrm{CNT}, \mathrm{PEG}$ CNT, 3-MA plus $\mathrm{COOH}-\mathrm{CNT}$ or 3-MA. In the 3-MA only group, 3-MA (15 mg/kg) was injected intraperitoneally twice. In the rescue group, 3-MA was injected intraperitoneally at 4 and $1 \mathrm{~h}$ before $\mathrm{COOH}-\mathrm{CNT}$. After $24 \mathrm{~h}$, mice were killed and the lungs were weighed for the wet weight. The dry weight of the lungs was obtained by drying them in the oven at $55^{\circ} \mathrm{C}$ overnight.

Statistical analyses. All data are shown as mean \pm s.e.m. and statistica analyses were conducted using the student $t$-test.

\section{Conflict of interest}

The authors declare no conflict of interest.

Acknowledgements. We thank Helen Pickersgill for helpful discussions and for editing the manuscript. This work is supported by the National Natural Science Foundation of China (30625013 and 30623009) and the Ministry of Science and Technology of China (2009ZX10004-308, 2009CB522105 and 2011CB933504).

1. Xia T, Li N, Nel AE. Potential health impact of nanoparticles. Annu Rev Public Health 2009; 30: $137-150$

2. Byrne JD, Baugh JA. The significance of nanoparticles in particle-induced pulmonary fibrosis. Mcgill J Med 2008; 11: 43-50.

3. Mossman BT, Borm PJ, Castranova V, Costa DL, Donaldson K, Kleeberger SR. Mechanisms of action of inhaled fibers, particles and nanoparticles in lung and cardiovascular diseases. Part Fibre Toxicol 2007; 4: 4

4. Song Y, Li X, Du X. Exposure to nanoparticles is related to pleural effusion, pulmonary fibrosis and granuloma. Eur Respir J 2009; 34: 559-567.

5. Pope III CA, Ezzati M, Dockery DW. Fine-particulate air pollution and life expectancy in the United States. N Engl J Med 2009; 360: 376-386.

6. Kostarelos K, Bianco A, Prato M. Promises, facts and challenges for carbon nanotubes in imaging and therapeutics. Nat Nanotechnol 2009; 4: 627-633.

7. Bianco A, Kostarelos K, Prato M. Applications of carbon nanotubes in drug delivery Curr Opin Chem Biol 2005; 9: 674-679.

8. Liu Z, Chen K, Davis C, Sherlock S, Cao Q, Chen X et al. Drug delivery with carbon nanotubes for in vivo cancer treatment. Cancer Res 2008; 68: 6652-6660.

9. Bianco A, Kostarelos K, Partidos CD, Prato M. Biomedical applications of functionalised carbon nanotubes. Chem Commun Camb 2005; 7: 571-577.

10. Chen J, Chen S, Zhao X, Kuznetsova LV, Wong SS, Ojima I. Functionalized single-walled carbon nanotubes as rationally designed vehicles for tumor-targeted drug delivery. J Am Chem Soc 2008; 130: 16778-16785.

11. Chou CC, Hsiao HY, Hong QS, Chen $\mathrm{CH}$, Peng YW, Chen HW et al. Single-walled carbon nanotubes can induce pulmonary injury in mouse model. Nano Lett 2008; 8: 437-445.

12. Shvedova AA, Fabisiak JP, Kisin ER, Murray AR, Roberts JR, Tyurina YY et al. Sequential exposure to carbon nanotubes and bacteria enhances pulmonary inflammation and infectivity. Am J Respir Cell Mol Biol 2008; 38: 579-590.

13. Shvedova AA, Kisin ER, Mercer R, Murray AR, Johnson VJ, Potapovich Al et al. Unusual inflammatory and fibrogenic pulmonary responses to single-walled carbon nanotubes in mice. Am J Physiol Lung Cell Mol Physiol 2005; 289: L698-L708.

14. Lam CW, James JT, McCluskey R, Hunter RL. Pulmonary toxicity of single-wall carbon nanotubes in mice 7 and 90 days after intratracheal instillation. Toxicol Sci 2004; 77: 126-134.

15. Levine B, Klionsky DJ. Development by self-digestion: molecular mechanisms and biological functions of autophagy. Dev Cell 2004; 6: 463-477.

16. Mizushima N, Levine B, Cuervo AM, Klionsky DJ. Autophagy fights disease through cellular self-digestion. Nature 2008; 451: 1069-1075.

17. Baehrecke EH. Autophagy: Dual roles in life and death? Nat Rev Mol Cell Biol 2005; 6 : 505-510.

18. Scarlatti F, Granata R, Meijer AJ, Codogno P. Does autophagy have a license to kill mammalian cells? Cell Death Differ 2009; 16: 12-20.

19. Zabirnyk O, Yezhelyev M, Seleverstov O. Nanoparticles as a novel class of autophagy activators. Autophagy 2007; 3: 278-281.

20. Li C, Liu H, Sun Y, Wang H, Guo F, Rao S et al. PAMAM nanoparticles promote acute lung injury by inducing autophagic cell death through the Akt-TSC2-mTOR signaling pathway. J Mol Cell Biol 2009; 1: 37-45.

21. Seleverstov O, Zabirnyk O, Zscharnack M, Bulavina L, Nowicki M, Heinrich JM et al. Quantum dots for human mesenchymal stem cells labeling. A size-dependent autophagy activation. Nano Lett 2006; 6: 2826-2832.

22. Yamawaki $\mathrm{H}$, Iwai $\mathrm{N}$. Cytotoxicity of water-soluble fullerene in vascular endothelial cells. Am J Physiol Cell Physiol 2006; 290: C1495-C1502.

23. Driscoll KE, Costa DL, Hatch G, Henderson R, Oberdorster G, Salem H et al. Intratracheal instillation as an exposure technique for the evaluation of respiratory tract toxicity: uses and limitations. Toxicol Sci 2000; 55: 24-35.

24. Klionsky DJ, Abeliovich H, Agostinis P, Agrawal DK, Aliev G, Askew DS et al. Guidelines for the use and interpretation of assays for monitoring autophagy in higher eukaryotes. Autophagy 2008; 4: 151-175.

25. Kabeya Y, Mizushima N, Ueno T, Yamamoto A, Kirisako T, Noda T et al. LC3, a mammalian homologue of yeast Apg8p, is localized in autophagosome membranes after processing. EMBO J 2000; 19: 5720-5728.

26. Levine B. Cell biology: autophagy and cancer. Nature 2007; 446: 745-747.

27. Seglen PO, Gordon PB. 3-Methyladenine: specific inhibitor of autophagic/lysosomal protein degradation in isolated rat hepatocytes. Proc Natl Acad Sci USA 1982; 79: 1889-1892.

28. Rubinsztein DC, Gestwicki JE, Murphy LO, Klionsky DJ. Potential therapeutic applications of autophagy. Nat Rev Drug Discov 2007; 6: 304-312.

29. Sarkar S, Ravikumar B, Floto RA, Rubinsztein DC. Rapamycin and mTOR-independent autophagy inducers ameliorate toxicity of polyglutamine-expanded huntingtin and related proteinopathies. Cell Death Differ 2009; 16: 46-56.

30. Meijer AJ, Codogno P. Regulation and role of autophagy in mammalian cells. Int J Biochem Cell Biol 2004; 36: 2445-2462.

31. Klionsky DJ. Autophagy: from phenomenology to molecular understanding in less than a decade. Nat Rev Mol Cell Biol 2007; 8: 931-937.

32. Research L. The Nanotech Report, 4th edn. Lux Research Inc: New York, NY, 2006.

33. Nel A, Xia T, Madler L, Li N. Toxic potential of materials at the nanolevel. Science 2006; 311: $622-627$.

34. Lam CW, James JT, McCluskey R, Arepalli S, Hunter RL. A review of carbon nanotube toxicity and assessment of potential occupational and environmental health risks. Crit Rev Toxicol 2006; 36: 189-217.

35. Hedrick SM, Ch'en IL, Alves BN. Intertwined pathways of programmed cell death in immunity. Immunol Rev 2010; 236: 41-53.

36. Scarlatti F, Maffei R, Beau I, Codogno P, Ghidoni R. Role of non-canonical Beclin 1 -independent autophagy in cell death induced by resveratrol in human breast cancer cells. Cell Death Differ 2008; 15: 1318-1329. published by Nature Publishing Group. This work is licensed under the Creative Commons Attribution-Noncommercial-Share Alike 3.0 Unported License. To view a copy of this license, visit http:// creativecommons.org/licenses/by-nc-sa/3.0/ 